\title{
Review
}

\section{Travel-acquired Japanese encephalitis and vaccination considerations}

\author{
Androula Pavli, Helena C Maltezou \\ Travel Medicine Office, Department for Interventions in Health-Care Facilities, Hellenic Center for Disease Control \\ and Prevention, Athens, Greece
}

\begin{abstract}
Japanese encephalitis (JE) is a serious arboviral disease caused by a virus of the genus Flavivirus. Japanese encephalitis is the most common vaccine-preventable virus causing encephalitis in Asia, affecting more than 50,000 persons and leading to 15,000 fatalities per year in endemic countries. For most travelers to Asia, the risk of Japanese encephalitis infection is extremely low and depends on destination, duration of travel, season, and activities. This article reviews travel-acquired Japanese encephalitis with a focus on epidemiology and prevention in the light of the newly available options for active immunization against Japanese encephalitis which have become available, and of the increasing popularity of travels to Japanese encephalitis endemic countries.
\end{abstract}

Key words: Japanese-encephalitis; vaccination; travelers.

J Infect Dev Ctries 2015; 9(9):917-924. doi:10.3855/jidc.5108.

(Received 10 April 2014 - Accepted 01 April 2015)

Copyright (C) 2015 Pavli et al. This is an open-access article distributed under the Creative Commons Attribution License, which permits unrestricted use, distribution, and reproduction in any medium, provided the original work is properly cited.

\section{Introduction}

Japanese encephalitis (JE) is a serious arboviral disease, caused by a single-stranded RNA virus that belongs to the genus Flavivirus. JE is an inflammatory disease affecting the central nervous system including the cerebrum, the cerebellum, and the spinal cord. JE is the most common vaccine-preventable encephalitis in Asia and occurs in annual epidemics or endemically in many Asian countries [1-4].

Globally JE affects more than 50,000 persons and causes 15,000 deaths per year in endemic countries [5]. Nearly 3 billion people, approximately $60 \%$ of the world's population, are estimated to be at risk for Japanese Encephalitis virus (JEV) infection [6]. For most travelers to Asia, the risk for JE infection is extremely low and depends on destination, duration, season, and activities and it can occur among people of any age. The overall incidence of JE in travelers is estimated to be $<1$ case per 1 million travelers from non endemic countries to Asia [4]. Although JE rarely affects travelers, its serious consequences and unpredictable epidemiology makes its prevention a very important part of the pre-travel consultation [6]. This article reviews travel-acquired JE with a focus on epidemiology and prevention considering the availability of new vaccines with improved safety profiles.

\section{Methods}

PubMed database was searched for the period between 1992 and 2014, using the words 'Japanese encephalitis', 'imported', 'travelers', and 'travelacquired'. Articles presenting original data on imported 'Japanese encephalitis' cases were included in our review, and review articles were also studied. The reference lists of these articles were also studied.

Study selection criteria for a case included a travel-associated JE case which was defined as a published report of JE in a traveler from a nonendemic country who had visited or lived in an Asian or Western Pacific country with JEV endemic transmission. A traveler was defined as a tourist traveling for recreation, an expatriate, a migrant, a traveler visiting friends and relatives, working into a humanitarian aid project, or a soldier. Articles that described travel-associated cases occurred during the period 1992-2014 were selected.

\section{Transmission}

JEV is transmitted mainly by the vector Culex tritaeniorhynchus in the most endemic regions in Asia, particularly in rural areas as it breeds in rice paddies and in connecting canals. It is an evening- and nighttime-biting mosquito that feeds outdoor and 
preferentially on large domestic animals and birds and only infrequently on humans $[1,5,7,10]$. In endemic areas, JEV is maintained in nature in an enzootic cycle between vector mosquitoes and aquatic birds forming the natural animal reservoirs, and pigs as amplifying vertebrate hosts. The infected mosquitoes transmit the virus to human and horses. However, JEV cannot be transmitted from humans or horses to biting mosquitoes due to the low viremia; therefore humans or horses are considered dead-end hosts $[5,7,8]$. The climate, especially temperature and rainfall affect the number and mosquito activity. Rice cultivation and other agricultural procedures may influence the density of mosquitos which eventually affects the transmission cycle of JEV. In temperate regions, transmission of JEV follows a seasonal pattern, leading to large epidemics; the vector is present in greatest density from May through December whereas in tropical areas, transmission is year-round, with a peak during the rainy season [10].

\section{Epidemiology}

JE occurs throughout most of Asia and sporadically in northern Australia, Queensland and Torres Strait islands, and parts of the western Pacific [1-3]. JEV results in an asymptomatic infection in most of the cases; it is primarily an infection affecting children since adults acquire immunity through natural infection during childhood. JE has a 20\%-30\% mortality rate. Among those who survive, the $30 \%$ $50 \%$ have serious neurologic, cognitive, and psychiatric sequelae [4,5]. The disease was firstly recognized in temperate areas of Asia including Japan, Korea, Taiwan, and in the mainland in China; however, in the past few decades an increased JEV transmission has been reported in Southeast Asia, India, Bangladesh, Sri Lanka, and Nepal [4,9]. In the late $1980 \mathrm{~s}$, in the 16 Asian countries considered endemic at that time, the overall annual incidence was 2 per 100,000 [10]. In the 1990s, JEV spread east and was recognized for the first time in Saipan and then in Australia, initially in the outer Torres Strait islands and subsequently on the northern mainland; JE virus infection was detected in 1995 among residents or domestic pigs on at least nine outer Torres Strait islands and two cases of JE were reported in north Queensland in 1998, including one acquired on the Australian mainland $[2,3,11]$. In 2000, it was estimated that in the absence of vaccination 175,000 cases of JE would occur annually among Asian children up to 14 years of age living in rural areas, after the assumption of an age-group-specific incidence of 25 cases per 100,000 residents [12]. According to recent data from 24 JE-endemic countries, the estimate of the global incidence of JE remains substantial, despite improvements in vaccination coverage; approximately 67,900 JE cases occur annually with an overall incidence of 1.8 per 100,000 residents, of which only about $10 \%$ are reported to the World Health Organization [1]. Nearly half of these cases occur in China (excluding Taiwan) and approximately $75 \%$ occur in children aged $0-14$ years (incidence: 5.4 per 100,000). The majority $(81 \%)$ of the cases occur in areas with well established or developing JE vaccination programmes [1]; this may reflect better surveillance and case-reporting in such areas as well as the epidemiological distribution of JE, since vaccination programmes are more likely to be implemented in areas with the highest risk of JEV transmission.

Contributing factors to the geographic expansion of the disease include population shifts or changes in climate, agricultural practices, ecology, animal husbandry, or migratory bird patterns which may lead to further spread, beyond Asia and the western Pacific [9].

\section{Epidemiology in travelers}

The overall incidence of JE among people from non endemic countries traveling to Asia is estimated to be $<1$ case per 1 million travelers [4]. The risk incidence of JE in travelers was estimated according to the total number of case reports from 1978 to 2008, the number of trips made by European travelers to JE endemic regions, and total doses of JE vaccines sold in two study countries (United Kingdom and Switzerland); data about the proportion of those travelers who received JE vaccination was retrieved from a London and a Basel travel clinic and this was related to vaccine prescriptions in United Kingdom and Swiss travelers [13]. The estimated incidence was 1.3 cases/year/7.1 million visits of 17 million travelers of potential risk [13]. Although JE incidence is extremely low in travelers, we may expect a potential rise given the increasing popularity of travels to JE endemic countries in particular to Southeast Asia, a region which showed a considerable growth of international arrivals. The number of international travelers to Southeast Asia increased from 21.2 million in 1990 to 36.1 million in 2000 and 84.6 million in 2012 , which corresponds to an $8.3 \%$ average annual increase from 2005 to 2012 [14]. 
Table 1. Characteristics of published Japanese encephalitis cases among travelers, 1992-2014

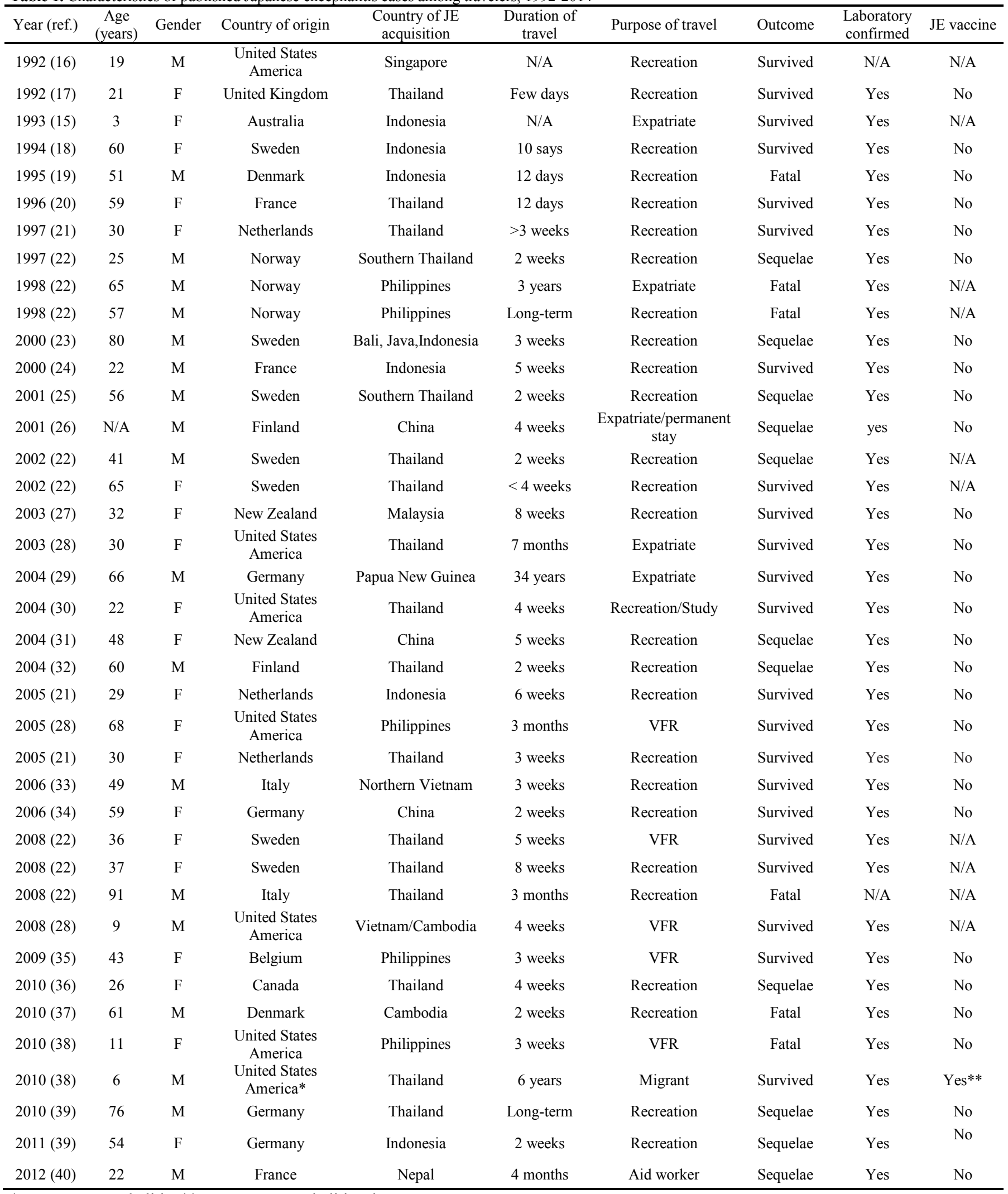

*Japanese Encephalitis, ** Japanese Encephalitis Virus 
An increasing number of cases have been reported during the past decades. From 1973 through 2011, there were 58 published reports of JE in travelers from non- endemic countries [15-39]. Contributing factors for acquisition of JE infection include long-term $(\geq 1$ month) stay in endemic areas, travel during an epidemic and increased popularity of outdoor activities in rural areas [4]. Although long-term travelers, expatriates and travelers who stay in rural areas with active JE virus transmission are exposed to a risk similar to the susceptible local population, short-term ( $<1$ month) travelers might be also considered at increased risk if they have extensive outdoor or nighttime exposure in rural areas during periods of active transmission [4,17-21,23,25,33-35,37-39]. From 1992 (when a mouse brain derived inactivated JE vaccine was licensed in the United States) through 2011, 7 JE cases among US travelers have been reported to the United States Centers for Disease Control and Prevention [4].

According to a recent review of the literature, a total of 39 travel-related JE cases were reported worldwide during 1992-2014 (Table 1); the percentage of the total number of JE travel-associated cases that these 39 published cases represent is unknown. This is indicated by using some available national data; a recent Scandinavian review revealed that among Scandinavian cases, 54\% that occurred during 19942008 was reported in literature [22]. In addition, travelers may develop symptoms during their travel, since the incubation time of JE is 5-15 days and therefore specific diagnosis and reporting may be missed or the patient may be treated abroad.

In the current review $43.6 \%$ of the identified cases were mainly acquired during travel to Southeast Asia, in particular Thailand (Table 1). More than one third of all cases were reported by Scandinavian countries (35.9\%). Nearly half of them $(48.7 \%)$ were men,
$20.5 \%$ were over 60 years of age, and $10.3 \%$ were children under 11 years of age. Being a child and in particular visiting friends and relatives increases the risk of acquiring the disease (Table 1); an example is the case of an 11-year old young girl who visited her relatives in Philippines [38]. Of all cases, $69.2 \%$ of them traveled for recreational purposes whereas $51.2 \%$ and $43.5 \%$ were long-term ( $\geq 1$ month) and short-term $(<1$ month) travelers, respectively (Table 1$)$. The number of cases amongst short-term travelers is high despite their lower attack rate; this rate looks comparatively high and may be related to the higher number of short-term travelers. Long-term travel to JE endemic areas is considered an important contributing factor for the acquisition of JE (Table 2); however, it is particularly surprising that among the cases reported many visited JE endemic areas for a short period of time. Although some travelers visited their destination for few days, and for recreation, they may have short trips outside their luxury hotels [33], and spend time under very basic conditions with local population (Table 2); e.g. this is the case of a woman traveler to Bali who stayed a few nights in huts with local people [39] (Table 1). Furthermore, even short-term travel and staying under good conditions cannot exclude the risk of being exposed to Culex tritaeniorbynchus; this was the case of the 61-year old Danish traveler who visited Cambodia for 14 days [37] (Table 1). Examples of increased risk of acquiring JE when traveling to rural areas and being engaged in outdoor activities include the cases of the 26 year-old woman who trekked in forests and rice fields in Chiang Mai region in Thailand, the 76 year-old man who stayed in villages in Thailand and the 54 year-old woman mentioned above who hiked across Bali [36,39] (Tables 1 and 2).

Travelers visiting friends and relatives (VFRs) and expatriates accounted for $12.8 \%$ and $10.2 \%$ of all

Table 2. Travel characteristics to be considered for travelers' risk assessment for JE* vaccination (adapted from references 9 and 48 ).

\begin{tabular}{|c|c|}
\hline Destination & Most areas of Asia and some parts of western Pacific \\
\hline Current outbreaks & Large, focal outbreaks of JE suggest extensive active JEV** transmission in that area \\
\hline Area of travel & Travel itinerary including rural agricultural areas (mainly with rice production and flooding irrigation) \\
\hline Type of accommodation & $\begin{array}{l}\text { Lack of availability of air conditioning, screens, or bed nets increases the risk of exposure to JE-infected } \\
\text { mosquitoes }\end{array}$ \\
\hline Season & $\begin{array}{l}\text { JEV transmission is seasonal in most temperate areas of (disease usually peaks in summer) and in the } \\
\text { subtropics and tropics, patterns vary, and human disease can occur year-round or can be sporadic }\end{array}$ \\
\hline Duration of travel & $\begin{array}{l}\text { Prolonged duration of stay. Travel-associated JE cases are mainly reported among expatriates or long- } \\
\text { term travelers ( } \geq 1 \text { month) } \\
\text { No specific duration of travel puts a traveler at risk for JE; however a longer itinerary increases the } \\
\text { possibility of traveler's exposure to JEV-infected mosquitoes }\end{array}$ \\
\hline Activities & $\begin{array}{l}\text { Outdoor activities (e.g., trekking, biking, camping, hiking, fishing, hunting, or farming), in particular at } \\
\text { night or evening, increase the risk of exposure to mosquitoes }\end{array}$ \\
\hline
\end{tabular}


cases identified in our review, respectively. VFRs are also at higher risk of exposure to JEV, in particular when staying in rural areas, as for the 43 year old woman who visited her relatives in the rural region of Luzon in Philippines (Tables 1 and 2) [35].

The overall fatality rate in travelers in the current review was $15.4 \%$ (Table 1) and sequelae such as neurological deficits, psychomotor and cognitive impairment were reported in $28.2 \%$ of patients. There was no history of pre-travel vaccination against JE in $71.8 \%$ of the cases. Only one patient had a history of vaccination, however there were no records. This information was not available in the remaining of the cases. Last-minute decision for travel may be a likely reason for some travelers not to consult a travel clinic for vaccination [36].

A small proportion of cases reported in the current review were imported from regions with major rains and acquired outside the wet season (from May to September) e.g. in popular tourist destinations in Southern Thailand $[22,25,32,39]$. This may be explained by the preference of travelers of visiting these destinations during the dry season in order to avoid the rainy season, or due to the unpredictability of the rainy season as a result of climate changes.

\section{Clinical manifestations and diagnosis}

Most of JE infections in humans are asymptomatic; only less than $1 \%$ of infected individuals develop clinical disease. The incubation period of JE infection is 5-15 days. Symptomatic JEV infection presents with nonspecific febrile illness, aseptic meningitis or encephalitis. Encephalitis is the most common presentation of JEV infection and presents with alteration in sensorium, seizures and focal neurological deficit. Illness usually begins with sudden onset of fever, headache, and vomiting. Mental status changes, focal neurologic deficits, generalized weakness, and movement disorders may develop over the next few days [41]. Altered sensorium, convulsions, especially among children, and headache are the main symptoms for hospitalization usually by the third day after onset. Acute flaccid paralysis may occur due to anterior horn cell involvement $[5,41]$. Other neurological features include a wide variety of movement disorders such as hyperkinesis, transient Parkinsonian features including choreoathetoid movements, tremor, and dystonia (limb, axial, orofacial). The features of brain stem involvement consist of opsoclonus, gaze palsies, and pupillary changes with waxing and waning character. Many non-neurological features of prognostic importance may also occur and include abnormal breathing patterns, pulmonary edema, and upper gastrointestinal hemorrhage $[5,41]$. JE mainly affects thalamus, corpus striatum, brainstem and spinal cord as revealed by MRI and on autopsy studies. Coinfection of JE and cysticercosis may also occur due to the important role of pigs in the life cycle of both JEV and cysticercosis [41].

The case-fatality ratio is approximately $20 \%-30 \%$. Among survivors, $30 \%-50 \%$ have serious neurologic, cognitive, or psychiatric sequelae [9]. However, progressive improvement may occur in all the parameters consisting of psychological disturbances, higher cerebral dysfunction, speech disorders, extrapyramidal, pyramidal features, and hypothalamic disturbances, cranial nerve disorders and seizures. Some non disabling features like dysarthria and corticospinal features without paralysis may persist in some patients [42]. A large study about a 14-year follow of survivors of JE revealed that the majority of cases improved between 6 months (55\%) to 1 year $(78 \%)$. Only some of the cases with the abovementioned neurological disorders improved between 5 to 14 years [42].

\section{Prevention of infection}

The best way to prevent mosquito borne infections such as JE is to avoid mosquito bites, regardless of vaccination status; avoiding outdoor activities or taking preventive measures such as using insect repellent during peak biting hours, wearing appropriate clothes such as long-sleeved shirts and long pants, sleep under permethrin impregnated bed nets when accommodations are not adequately screened or air conditioned and using spatial repellents $[4,9]$.

Various vaccines against Japanese encephalitis are available since 1950 [43]. First-generation JE vaccines have been widely used for the past few decades: (i) mouse brain derived inactivated vaccines, (ii) inactivated vaccines cultivated on primary hamster kidney cells and (iii) live attenuated vaccine based on strain SA 14-14-2 and cultivated on primary hamster kidney cells [44].

JE mouse brain vaccine has been used for several decades in USA (licensed in 1992) and Europe (BIKEN; distributed as JE-Vax by Sanofi Pasteur, Lyon, France); however, production of this JE vaccine has ceased by the manufacturer due to its poorly understood worrisome safety profile $[44,45]$. A second formalin-inactivated vaccine which was cultivated-in and used the P3 strain was developed in China in 1968 
and widely used [44,45]. A live-attenuated SA14-14-2 vaccine was licensed in 1988 and is currently used in Nepal, India, Sri Lanka, Thailand and South Korea. The vaccine has demonstrated an excellent safety profile and effectiveness [45].

Second-generation JE vaccines with lower dosage schemes and better safety profiles provide important new options for protection of residents and travelers. Two new vaccines have been recently developed: 1) IC51 Japanese encephalitis vaccine or IXIARO developed by Intercell AG, and 2) chimeric Japanese encephalitis vaccine, developed by Acambis, application for licensure is ongoing $[44,45]$.

The IC51 IXIARO vaccine is a purified, formalininactivated, whole-virus JE vaccine (in Australia and New Zealand is available as JESPECT; Intercell AG, Vienna, Austria). The product is approved in the USA for persons aged $\geq 17$ years, and in Europe, Canada, Switzerland and Australia. IC51 is manufactured by Intercell Biomedical (Livingston, UK) and is distributed in the USA by Novartis vaccines (Cambridge, USA) [9,44].

ChimeriVax-Japanese encephalitis vaccine is a lyophilized formulation of a chimeric virus incorporating the structural genes (prM and E) from Japanese encephalitis strain SA 14-14-2 into the nonstructural genes of the yellow fever vaccine virus, yellow fever $17 \mathrm{D}$ [46]. This vaccine was developed by Sanofi Pasteur which has filed for marketing authorization with the Therapeutic Goods Administration in Australia and the Food and Drug Administration in Thailand [47].

Recommendations for JE vaccination of travelers aims at limiting the use of mouse brain-derived vaccine due to its high risk of severe vaccine related adverse reactions including neurological (e.g. encephalitis, encephalopathy, seizures and peripheral neuropathy) and hypersensitivity side effects (e.g. angioedema) [48]. The discontinued availability of the mouse brain-derived vaccine and licensure of a new, well-tolerated cell-culture-derived vaccine IC51 with an excellent safety profile, justifies the reconsideration of the benefit-risk ratio of vaccination of travelers in order to prevent the occurrence of severe, but vaccinepreventable JE cases [48]. These considerations are reflected in revised recommendations (March 2010) by the United States Advisory Committee on Immunization Practices [9]. Clinical trials revealed that local and systemic adverse events caused by the culture-derived vaccine IC51 are similar to those reported for the mouse-derived vaccine, or placebo adjuvant alone; however, recipients of the former had significantly fewer local reactions and no serious hypersensitivity adverse events [49].

When recommending the use of JE vaccine for travelers, clinicians must weigh the overall low risk of travel-acquired JE, the high fatality rate and sequelae of JE, the low probability of serious adverse events of vaccination, and the cost of the vaccine. Revised recommendations include vaccination with $\mathrm{JE}$ vaccine for travelers visiting areas of Asia endemic for JE who will be in a high-risk setting based on season, location, duration, and activities [9]. Furthermore, travelers should be advised about the risks of JEV infection and characteristics of available vaccines [48] (Table 2). Factors to consider when evaluating a traveler's risk for JEV exposure before JE vaccination are described on Table $2[9,48]$. Other factors to be taken into account include age (individuals $\geq 50$ and children $\leq$ 10 years of age are at increased risk for serious morbidity and death), and individuals with chronic conditions such as hypertension, diabetes mellitus, chronic renal disease, solid organ transplant, central nervous system devices, and cerebrospinal fluid leakage $[4,9,48]$. Furthermore, vaccination should also be considered for pregnant women, balancing the possibility of unknown vaccine-related risks. Points supporting vaccination include availability of a safe and efficacious vaccine, serious and untreatable disease, unknown risk of exposure during travel, underreported and undetected cases, frequent trips, VFRs in rural areas, and possible risk during nontypical transmission season. The very low incidence of $\mathrm{JE}$ in travelers, the possibility of risk areas not to be visited by most travelers, the seasonal pattern and the possible side effects and high cost of the vaccine are points not supporting vaccination [13].

\section{Conclusions}

Japanese encephalitis is the most common vaccine-preventable viral encephalitis in Asia. Although the incidence of JE is very low in travelers, the number of international travels to Southeast Asia has been increasing and the risk of acquiring a serious infection remains of great concern. Previous recommendations for JE vaccination for travelers were focusing on minimizing exposure to a mouse brainderived vaccine due to poorly understood adverse reactions in face of a very low risk of infection. Vero cell-culture based Japanese encephalitis vaccine, IC51, was licensed in Europe and the United States in 2009 and replaced the inactivated mouse brain-derived JE vaccine. With the availability of new vaccines with improved safety profiles, it is imperative to reconsider 
the benefit-risk ratio for JE vaccination of travelers, based on a careful risk assessment tailored for every traveler.

\section{References}

1. Campbell GL, Hills SL, Fischer M, Jacobson JA, Hoke CH, Hombach JM, Marfin AA, Solomon T, Tsai TF, Tsu VD, Ginsburg AS (2011) Estimated global incidence of Japanese encephalitis: a systematic review. Bull World Health Organ 89: 766-774

2. Hanna JN, Ritchie SA, Phillips DA, Shield J, Bailey MC, Mackenzie JS, Poidinger M, McCall BJ, Mills PJ (1996) An outbreak of Japanese encephalitis in the Torres Strait, Australia, 1995. Med J Aust 165: 256

3. Hanna JN, Ritchie SA, Phillips DA, Lee JM, Hills SL, van den Hurk AF Pyke AT, Johansen CA, Mackenzie JS (1999) Japanese encephalitis in north Queensland, Australia, 1998. Med J Aust 170: 533-536.

4. Centers for Disease Control and Prevention. Travelers' health: yellow book. Available at: http://wwwnc.cdc.gov/travel/yellowbook/2014/chapter-3infectious-diseases-related-to-travel/japanese-encephalitis. Accessed on December 9, 2013.

5. Misra UK, Kalita J (2010) Overview: Japanese encephalitis. Prog Neurobiol 91: 108-20.

6. Oya A, Kurane I ((2007) Japanese encephalitis for a reference to international travelers. J Travel Med. 4: 259-268.

7. Rosen L (1986) The natural history of Japanese encephalitis virus. Annu Rev Microbiol 40: 76-79

8. Halstead SB, Jacobson J. Japanese encephalitis vaccines. In: Plotkin SA, Orenstein WA, Offit PA, editors. Vaccines. 5th ed. Philadelphia: Elsevier; 2008. pp. 311-352.

9. Fischer M, Lindsey N, Staples JE, Hills S (2010) Centers for Disease Control and Prevention (CDC). Japanese encephalitis vaccines: recommendations of the Advisory Committee on Immunization Practices (ACIP). MMWR Recomm Rep 59: 127.

10. Burke DS, Leake CJ. Japanese encephalitis. In: Monath TP, editor. The arboviruses: epidemiology and ecology, Vol. 3. Boca Raton: CRC Press; 1988. pp. 63-92.

11. Paul WS, Moore PS, Karabatsos N, Paul WS, Moore PS, Karabatsos N, et al (1993) Outbreak of Japanese encephalitis on the island of Saipan, 1990. J Infect Dis 167: 1053-1058.

12. Tsai TF (2000) New initiatives for the control of Japanese encephalitis by vaccination: minutes of a WHO/CVI meeting, Bangkok, Thailand, 13-15 October 1998 Vaccine 18(Suppl 2): $1-25$

13. Hatz C, Werlein J, Mutsch M, Hufnagel M, Behrens RH (2009) Japanese encephalitis: defining risk incidence for travelers to endemic countries and vaccine prescribing from the UK and Switzerland J Travel Med 16: 200-203.

14. World Tourism Organization. UNWTO Tourism Highlights 2013. Available at http://dtxtq4w60xqpw.cloudfront.net/sites/all/files/pdf/unwto highlights 13 en hr.pdf. Accessed on January 13, 2014.

15. Hills SL, Griggs AC, Fischer M (2010) Japanese encephalitis in travelers from non-endemic countries, 1973-2008. Am J Trop Med Hyg 82: 930-936.

16. Centers for Disease Control and Prevention (1993) Inactivated Japanese encephalitis virus vaccine. Recommendations of the advisory committee on immunization practices (ACIP). MMWR Morb Mortal Wkly Rep 42: 1- 16.

17. Burdon JT, Stanley PJ, Lloyd G, Jones NC (1994) A case of Japanese encephalitis. J Infect 28: 175-179.

18. Wittesjo B, Eitrem R, Niklasson B, Vene S, Mangiafico JA (1995) Japanese encephalitis after a 10-days holiday in Bali. Lancet 345: 856.

19. Buhl MR, Black FT, Andersen PL, Laursen A (1996) Fatal Japanese encephalitis in a Danish tourist visiting Bali for 12 days. Scand J Infect Dis 28: 189.

20. Bernard P, Jambaud E, Berbineau A, Brunot J, Flechaire A (19980 Japanese encephalitis: an exceptional imported arbovirus [in French]. Presse Med 27: 1327.

21. Delsing CE, Ardesch J, Nihom J, Mulder L, Kootstra GJ, Hylkema BS (2005) An unusual cause of meningoencephalitis: Japanese encephalitis [in Dutch]. Ned Tijdschr Geneeskd 149: 2423-2427.

22. Buhl MR, Lindquist L (2009) Japanese encephalitis in travelers: review of cases and seasonal risk. J Travel Med 16: 217-219

23. Ostlund MR, Kan B, Karlsson M, Vene S (2004) Japanese encephalitis in a Swedish tourist after traveling to Java and Bali. Scand J Infect Dis 36: 512-513.

24. Monnet FP (2003) Behavioral disturbances following Japanese B encephalitis. Eur Psychiatry 18: 269-273.

25. Widerstrom M (2001) [Japanese encephalitis in a traveller to Thailand.] Smittskydd 9: 97. Available at: http://www.smittskyddsinstitutet.se/smittskydd/. Accessed on January 13, 2014.

26. Siikamaki H (2002) Japanese encephalitis in a Finnish citizen-infected in Beijing [in Finnish]. Suomen Laakarilehti 40: 3989-3990.

27. Geraghty CM, McCarthy JS, (2004) Japanese encephalitis vaccine: is it being sufficiently used in travelers? Med J Aust 181: 269-270.

28. Centers for Disease Control and Prevention (2009) Japanese encephalitis among three U.S. travelers returning from Asia, 2003-2008. MMWR Morb Mortal Wkly Rep 58: 737-740.

29. Hanson JP, Taylor CT, Richards AR, Smith IL, Boutlis CS (2004) Japanese encephalitis acquired near Port Moresby: implications for residents and travelers to Papua New Guinea. Med J Aust 181: 282.

30. Centers for Disease Control and Prevention (2005) Japanese encephalitis in a U.S. traveler returning from Thailand, 2004. MMWR Morb Mortal Wkly Rep 54: 123-125

31. Cutfield NJ, Anderson NE, Brickell K, Hueston L, Pikholz C, Roxburgh RH (2005) Japanese encephalitis acquired during travel in China. Intern Med J 35: 497-498.

32. Lehtinen VA, Huhtamo E, Siikamaki H, Vapalahti O (2008) Japanese encephalitis in a Finnish traveler on a two-week holiday in Thailand. J Clin Virol 43: 93-95

33. Caramello P, Canta F, Balbiano R, Lipani F, Ariaudo S, De Agostini M, Calleri G, Boglione L, Di Caro A (2007) A case of imported JE acquired during short travel in Vietnam. Are current recommendations about vaccination broader? J Travel Med 14: 346-348

34. Reppel M, Landreh L, Gottschalk S, Schunkert H, Kurowski V, Seidel G (2009) Japanese encephalitis in Western Europe. Clin Neurol Neurosurg 111: 373-375.

35. Jeurissen A, Strauven T (2011) A case of aseptic meningitis due to Japanese encephalitis virus in a traveller returning from the Philippines. Acta Neurol Belg 111: 143-145. 
36. Langevin S, Libman M, Drebot MA, Laverdière M (2012) A case of Japanese encephalitis virus infection acquired during a trip in Thailand. J Travel Med. 19: 127-129.

37. Werlinrud AM, Christiansen CB, Koch A (2011) Japanese encephalitis in a Danish short-term traveler to Cambodia. Travel Med 18: 411-413.

38. Centers for Disease Control and Prevention (CDC) (2011) Japanese encephalitis in two children--United States, 2010. MMWR Morb Mortal Wkly Rep 60: 276-278.

39. Tappe D, Nemecek A, Zipp F, Emmerich P, Gabriel M, Günther S, Dobler G, Schmidt-Chanasit J, Stich A (2012) Two laboratory-confirmed cases of Japanese encephalitis imported to Germany by travelers returning from Southeast Asia. J Clin Virol 54: 282-285.

40. Lagarde S, Lagier JC, Charrel R, Quérat G, Vanhomwegen J, Desprès P, Pelletier J, Kaphan E (2014) Japanese encephalitis in a French traveler to Nepal. J Neurovirol 20: 99-102. doi: 10.1007/s13365-013-0226-2.

41. Sarkari NB, Thacker AK, Barthwal SP, Mishra VK, Prapann S, Srivastava D, et al (2012) Japanese encephalitis (JE). Part I: clinical profile of 1,282 adult acute cases of four epidemics. J Neurol 259: 47-57.

42. Sarkari NB, Thacker AK, Barthwal SP, Mishra VK, Prapann S, Srivastava D, Sarkari M (2012) Japanese encephalitis (JE) part II: 14 years' follow-up of survivors. J Neurol 259: 58-69.

43. Halstead SB, Jacobson J. Japanese encephalitis vaccines. In: Plotkin SA, OrensteinWAand Offit P, editors. Vaccines. Philadelphia: Saunders Elsevier; 2008

44. Wilder-Smith A, Halstead SB (2010) Japanese encephalitis: update on vaccines and vaccine recommendations. Curr Opin Infect Dis 23: 426-431.
45. Halstead SB, Thomas SJ (2011) New Japanese encephalitis vaccines: alternatives to production in mouse brain. Expert Rev Vaccines 10: 355-364.

46. Monath TP, McCarthy K, Bedford P, Johnson CT, Nichols R, Yoksan S, archesani R, Knauber M, Wells KH, Arroyo J, Guirakhoo F (2002) Clinical proof of principle for ChimeriVax: recombinant live, attenuated vaccines against flavivirus infections. Vaccine 20: 1004-1018.

47. Halstead SB, Thomas SJ (2010) Japanese encephalitis: new options for active immunization. Clin Infect Dis 50: 11551164.

48. Burchard GD, Caumes E, Connor BA, Freedman DO, Jelinek T, Jong EC, von Sonnenburg F, Steffen R, Tsai TF, WilderSmith A, Zuckerman J (2009) Expert opinion on vaccination of travelers against Japanese encephalitis. J Travel Med 16: 204-216.

49. Schuller E, Jilma B, Voicu V, Golor G, Kollaritsch H, Kaltenböck A, Klade C, Tauber E (2008) Long-term immunogenicity of the new Vero cell-derived, inactivated Japanese encephalitis virus vaccine IC51 Six and 12 month results of a multicenter follow-up phase 3 study. Vaccine 26: 4382-4386.

\section{Corresponding author}

Dr. Maltezou, Department for Interventions in Health-Care Facilities, Hellenic Centre for Disease Control and Prevention, 3-5 Agrafon Street, Athens, 15123 Greece

Phone: $30-210-5212-175$

Fax: 0-210-5212-177

Email: helen-maltezou@ath.forthnet.gr

Conflict of interests: No conflict of interests is declared. 